Illinois State University

ISU ReD: Research and eData

Theses and Dissertations

6-11-2019

\title{
The Relationship Between Childhood Sexual Abuse, Attachment Style, Rejection, and Risk Recognition
}

Jordan E. Marshall

Illinois State University, jemars1@ilstu.edu

Follow this and additional works at: https://ir.library.illinoisstate.edu/etd

Part of the Psychology Commons

\section{Recommended Citation}

Marshall, Jordan E., "The Relationship Between Childhood Sexual Abuse, Attachment Style, Rejection, and Risk Recognition" (2019). Theses and Dissertations. 1144.

https://ir.library.illinoisstate.edu/etd/1144

This Thesis is brought to you for free and open access by ISU ReD: Research and eData. It has been accepted for inclusion in Theses and Dissertations by an authorized administrator of ISU ReD: Research and eData. For more information, please contact ISUReD@ilstu.edu. 


\section{THE RELATIONSHIP BETWEEN CHILDHOOD SEXUAL ABUSE, ATTACHMENT STYLE, REJECTION, AND RISK RECOGNITION}

\section{JORDAN E. MARSHALL}

\section{Pages}

The purpose of the study was to better understand the relationship between experiencing childhood sexual abuse, attachment, rejection, and risk recognition (risk appraisal and risk response). Participants consisted of 223 undergraduate women attending Illinois State University. A history of childhood abuse was reported by $37.7 \%$ of the participants. Participants completed a demographics questionnaire, the Hot Topics Survey, the Experiences in Close Relationships-Revised (ECR-R) questionnaire, and the Rejection Sensitivity Questionnaire, Adult version (A-RSQ). Participants were under the impression that information was being gathered for an online dating application algorithm and were randomly assigned to either a rejection condition or a non-rejection condition, in which they were either told the algorithm matched them two or eight people respectively. After the rejection manipulation, participants read through a risk recognition vignette comprised of 13 scenes and indicated when they would stop feeling comfortable in the situation and when they would end the interaction. No moderation relationship was found between rejection sensitivity, the rejection manipulation, and risk recognition. There was a significant mediation relationship found between history of childhood sexual abuse, anxious attachment, and rejection sensitivity. KEYWORDS: Childhood Sexual Abuse, Attachment, Rejection Sensitivity, Risk Recognition 
THE RELATIONSHIP BETWEEN CHILDHOOD SEXUAL ABUSE, ATTACHMENT

STYLE, REJECTION, AND RISK RECOGNITION

JORDAN E. MARSHALL

\author{
A Thesis Submitted in Partial \\ Fulfillment of the Requirements \\ for the Degree of \\ MASTER OF SCIENCE \\ Department of Psychology \\ ILLINOIS STATE UNIVERSITY
}

2019 
(C) 2019 Jordan E. Marshall 
THE RELATIONSHIP BETWEEN CHILDHOOD SEXUAL ABUSE, ATTACHMENT STYLE, REJECTION, AND RISK RECOGNITION

JORDAN E. MARSHALL

COMMITTEE MEMBERS:

Marla Reese-Weber, Chair

Jeffrey Kahn 


\section{ACKNOWLEDGMENTS}

I would like to thank my committee chair, Dr. Marla Reese-Weber for her steadfast support and guidance throughout the process of this study. The structure she provided throughout the process was critical to the success of the study. I would also like to thank my committee member, Dr. Jeffrey Kahn for all his helpful, supportive feedback. Finally, I would like to thank my friend and colleague, Emily Harms for her ideas during brainstorming sessions, her help collecting data, and the emotional support and humor she provided.

J. E. M. 


\section{CONTENTS}

Page

ACKNOWLEDGMENTS

TABLES

FIGURES

CHAPTER I: THE PROBLEM AND ITS BACKGROUND 1

CHAPTER II: LITERATURE REVIEW 3

Childhood Sexual Abuse $\quad 3$

$\begin{array}{ll}\text { Attachment and Rejection Sensitivity } & 7\end{array}$

Risk Recognition $\quad 12$

$\begin{array}{ll}\text { The Current Study } & 14\end{array}$

CHAPTER III: RESEARCH METHODOLOGY 18

$\begin{array}{ll}\text { Participants } & 18\end{array}$

$\begin{array}{ll}\text { Measures } & 19\end{array}$

$\begin{array}{ll}\text { Childhood Sexual Abuse } & 19\end{array}$

$\begin{array}{ll}\text { Adult Attachment Style } & 20\end{array}$

$\begin{array}{ll}\text { Rejection Sensitivity } & 20\end{array}$

$\begin{array}{ll}\text { Rejection Manipulation } & 21\end{array}$

Risk Recognition (Risk Appraisal and Risk Response) 22

$\begin{array}{ll}\text { Procedure } & 22\end{array}$

CHAPTER IV: RESULTS 24

$\begin{array}{ll}\text { CHAPTER V: DISCUSSION } & 28\end{array}$

Limitations and Future Directions 31 
$\begin{array}{ll}\text { REFERENCES } & 35\end{array}$

$\begin{array}{ll}\text { APPENDIX A: VIGNETTE } & 44\end{array}$

APPENDIX B: RESEARCH PARTICIPANT INFORMED CONSENT 49

$\begin{array}{ll}\text { APPENDIX C: PROCEDURE } & 51\end{array}$ 


\section{TABLES}

Table

Page

1. Attachment Styles Based on Representations of Self and Others

2. Correlations, Means, and Standard Deviations among Person-level Measures $(\mathrm{N}=223)$

3. Multiple Regression Analyses Predicting Risk Recognition from Rejection Sensitivity, Rejection Manipulation, and the Interaction between Rejection Sensitivity and Rejection Manipulation 


\section{FIGURES}

Figure $\quad$ Page

1. Hypothesized Mediation Model Connecting CSA and Rejection Sensitivity 15

2. Hypothesized Moderation Model Connecting Rejection Sensitivity and Risk Appraisal

3. Hypothesized Moderation Model Connecting Rejection Sensitivity and Risk Response

4. Hypothesized Risk Recognition Latency Relationships between Rejection Sensitivity and Rejection Manipulation for both Risk Appraisal and Risk Response

5. Hypothesis 1 Mediation Model Connecting CSA and Rejection Sensitivity 


\section{CHAPTER I: THE PROBLEM AND ITS BACKGROUND}

Childhood sexual abuse (CSA) is a pervasive concern. In their study of participants ages 15-17 years, Finkelhor, Shattuck, Turner, and Hamby (2014) found lifetime prevalence rates of sexual abuse to be $26.6 \%$ for females and $5.1 \%$ for males. CSA can include a variety of emotional and behavioral outcomes, including delinquent behaviors such as substance use (Bergen, Martin, Richardson, Allison, \& Roeger, 2004), risky sexual behaviors (Homma, Wang, Saewyc, \& Kishor, 2012), poor mental health (Fergusson, Boden, \& Horwood, 2008), and increased risk of revictimization (Conley et al., 2017; Messman-Moore \& Long, 2003). Messman-Moore and Long (2003) found victims of CSA to be 2 to 11 times more likely than non-victims to be sexually abused in adulthood. There are several factors that have been examined individually to understand the relationship between CSA and revictimization, including attachment (Finkelhor \& Browne 1985), rejection sensitivity (Feldman \& Downey, 1994), and risk recognition (Vanzile-Tamsen, Testa, \& Livingston, 2005; Wilson, Calhoun, \& Bernat, 1999). Missing in the existing research is how these factors interact to help explain revictimization.

Insecure attachment has been linked to motives for engaging in sexual intercourse such as reducing insecurity, feeling valued, impressing peers, and self-protection (Davis, Shaver, \& Verson, 2004; Schachner \& Shaver, 2004). Individuals with an insecure attachment style are more likely to report engaging in unwanted consensual sex due to fears that their partners would lose interest and because of a felt sense of obligation (Imett \& Peplau, 2002). Those with more insecure attachment styles also tend to be higher in rejection sensitivity than those with more secure attachment styles (Feldman \& Downey, 1994; Erozkan, 2009; Khoshkam, Bahrami, Ahmadi, Fatehizade, \& Etemadi, 2012). Those higher in rejection sensitivity more readily 
perceive and respond to rejection (Feldman \& Downey, 1994), so it is possible that they would engage in unwanted or risky sexual behaviors to avoid feeling rejected. In the current study, risk recognition had two components; risk appraisal and risk response. Risk appraisal is concerned with whether a person perceives a situation as unsafe. Risk response is concerned with whether a person removes themselves from the situation.

The population of interest is heterosexual women between 18 to 25 years old. This is the stage of emerging adulthood, in which individuals tend to develop more serious romantic relationships (Arnett, 2000), and CSA victims are likely to be revictimized (Reese-Weber \& Smith, 2011). The current study examined the potential relationship between CSA, attachment style, rejection sensitivity, and risk recognition. This is an important area to research, because those who experience CSA are more likely to experience sexual abuse in adulthood (Conley et al., 2017), and understanding the connections between the two will help prevent revictimization. 


\section{CHAPTER II: LITERATURE REVIEW}

\section{Childhood Sexual Abuse}

Finkelhor et al. (2014) found prevalence rates of CSA as $26.6 \%$ for females and $5.1 \%$ for males, with those committed by an adult perpetrator as $11.2 \%$ for females and $1.9 \%$ for males. The remaining cases of CSA were perpetrated by the victim's peers. Other studies have found similar prevalence rates. In their meta-analysis Stolenborgh, van IJzendoorn, and BakermansKranenburg (2011) found that 180 in 1,000 females and 76 in 1,000 males experienced childhood sexual abuse. Despite the prevalence of CSA, the literature on the subject does not use a consistent definition of CSA. Some studies include only cases that involve physical contact in their definition of CSA (Townsend \& Rheingold, 2013) while other studies employ a broader definition of CSA, including non-physical sexual abuse ("Prevent Child Abuse America", 2013). There are several negative outcomes associated with CSA, including delinquent behaviors (Bergen et al., 2004), risky sexual behavior (Homma et al., 2012), and poor mental health (Fergusson et al., 2008). Revictimization can also be an outcome of CSA (Conley et al., 2017). In a study on college students, $22.2 \%$ of participants reported experiencing sexual abuse prior to entering college, and $39.2 \%$ of those reporting sexual abuse before college reported revictimization during college (Conley et al., 2017). The purpose of the current study was to better understand the relationship between experiencing childhood sexual abuse and revictimization in adulthood, specifically concerning the outcomes of attachment, rejection, and risk recognition (risk appraisal and risk response).

Tyler (2002) conducted a literature review on the short-term outcomes of CSA. In this collective review of research, short-term outcomes of CSA included inappropriate sexual behavior and internalizing and externalizing problems in both early childhood and middle 
childhood. In addition, sexual abuse during middle school was linked to depression, suicide ideation, PTSD, and sexual anxiety. During adolescence, the outcomes were similar to the other age groups but also included risky sexual behaviors, substance use, gang involvement, attempting suicide, pregnancy, and running away. Other studies have found similar results, linking CSA to delinquent and antisocial behaviors (Bergen et al., 2004; Feiring, Miller-Johnson, \& Cleland, 2007), substance use (Bergen et al., 2004; Fergusson et al., 2008), risky sexual behaviors (Arriola, Louden, Doldren, \& Fortenberry, 2005; Homma et al., 2012), and poor mental health (Croysdale, Drerup, Bewsey, \& Hoffman, 2008; Fergusson et al., 2008).

There is a multitude of studies examining the long-term outcomes of CSA. Research has consistently found that those who experience CSA are more likely to be victims of sexual abuse in adulthood. In an 18-year longitudinal study, Barnes, Noll, Putman, and Trickett (2009) found that compared to non-abused women, women who experienced CSA were nearly two times as likely to experience both sexual and physical abuse in adulthood. Similarly, Messman-Moore and Long (2000) found that women who experienced CSA were more likely to be revictimized in adulthood than non-abused peers. Specifically, women who experienced CSA were more likely to report date rape, experience unwanted intercourse due to misuse of perpetrator's authority, be victim to physical and verbal abuse, and experience domination or isolation from their partner. In their longitudinal study, Noll, Horowitz, Bonanno, Trickett, and Putman (2003) found that, compared to non-abused participants, those who experienced CSA were more likely to report self-harm, be revictimized, and experience more lifetime traumas.

Both the short and long-term outcomes of CSA have been examined and conceptualized in the Traumagenic Dynamics model. Finkelhor and Browne (1985) created this conceptual model of four trauma-causing factors or traumagenic dynamics associated with CSA; traumatic 
sexualization, stigmatization, powerlessness, and betrayal. Finkelhor and Browne (1985)

formulated these traumagenic dynamics by reviewing the literature and creating categories based on the different types of outcomes found among CSA victims.

Traumatic sexualization is the process by which an individual's sexuality develops inappropriately due to the experience of CSA (Finkelhor \& Browne, 1985). There are several different ways that traumatic sexualization can develop. One way traumatic sexualization can occur is through repeatedly being treated in a sexually inappropriate way for one's age. Traumatic sexualization can also occur through exchanging sex for other things, thereby teaching the child to use sex as a way to manipulate others. Other ways traumatic sexualization can occur include through specific parts of the body being emphasized as more important, through misconceptions about sexual morality, and/or through fear being associated with sexuality (Finkelhor \& Browne, 1985). This can result in an individual being either hyposexualized or hypersexualized. Hyposexualization manifests as sexual aversion and sexual dysfunction. On the other hand, hypersexualization manifests as sexual risk taking and sexual preoccupation. As a result, those who experience CSA have been found to have higher levels of risky sexual behaviors (Fergusson, McLeod, \& Horwood, 2013; Filipas \& Ullman, 2006). In addition, experiencing CSA has been associated with younger age at first consensual intercourse, sexual aversion, pervasive pathological dissociation, and endorsing more attitudes indicative of sexual preoccupation (Noll, Trickett, \& Putman, 2003).

Stigmatization occurs when a child is blamed for their abuse experience or the abuse is kept a secret. Stigmatization encompasses the feelings of guilt, blame, and generally being bad (Finkelhor \& Browne, 1985). Research indicates that victims of CSA are more likely to report low self-esteem and experience self-blame (Fergusson et al., 2013). In their study, Filipas and 
Ullman (2006) found that more than half the participants blamed themselves at the time of abuse, and one-third currently blamed themselves. Individuals who blamed themselves were more likely to engage in maladaptive coping strategies in adulthood, including withdrawing from others, drug and alcohol use, engaging in risky sex behaviors, and aggressive behaviors. Filipas and Ullman (2006) also found that the most common coping strategy was trying to forget about the CSA and that those who engaged in maladaptive coping strategies were significantly more likely to be revictimized in adulthood.

Powerlessness refers to the victim's feelings of being unable to control what is happening (Finkelhor \& Browne, 1985). These feelings of powerlessness are brought about by the child's body repeatedly being intruded upon, the child's attempts at stopping the abuse failing, and the failure of other adults to intervene. CSA, and particularly feelings of powerlessness, has been linked to an increased risk of PTSD symptoms (Fergusson et al., 2013) as well as earlier onset of depression and a greater likelihood of self-harm (Gladstone et al., 2004). More specifically, Gladstone et al. (2004) compared adult women with depression who experienced CSA to adult women with depression who did not experience CSA. The women did not differ in severity of depression; however, women who experienced CSA had onset of depression at an earlier age. The women who experienced CSA were also more likely than those without a CSA history to be diagnosed with panic disorder and were more likely to self-harm.

Betrayal refers to the process and impact of a victim realizing someone they rely on to have their needs met has caused them harm (Finkelhor \& Browne, 1985). Betrayal can come about via the realization that one has been manipulated by a trusted person, one's well-being has been disregarded by a loved figure, and that one was not protected by other loved figures. A major area of research that falls within this category is the relationship between CSA and 
individual differences in attachment style. In their path analysis, Roche, Runtz, and Hunter (1999) demonstrated that individuals who experienced CSA had a less secure adult attachment style than those without a CSA history. Furthermore, a less-secure attachment style was predictive of poorer psychological adjustment. Similarly, Bifulco et al. (2006) found that experiencing childhood abuse, which included both physical and sexual abuse, was positively associated with having an insecure attachment style. The current study examined how the dynamic of betrayal, specifically attachment, might help explain the connection between CSA and revictimization. To better understand this outcome, the next section will review the literature on infant attachment and its relationship to later adult attachment.

\section{Attachment and Rejection Sensitivity}

Bowlby's (1982) attachment theory posits that individuals have an attachment system that serves the purposes of safety and survival through proximity seeking to an attachment figure. In infancy, these attachment figures are the individual's primary caregivers. Since the attachment system is a survival system, when it is activated other systems, such as the exploratory system, are inhibited. Once the individual feels safe again, the attachment system will turn off and other systems are no longer inhibited. For example, a 12-month-old boy is playing in the grass with his mother nearby. The boy's exploratory system is activated. A stranger approaches the boy, making the boy feel unsafe. Now the boy's attachment system is activated, and he runs to his mom. The mom comforts the boy, and he feels safe again. His attachment system turns off, allowing his exploratory system to turn back on, and he returns to playing.

There are individual differences in attachment style that are influenced by one's environment. These individual differences were examined by Ainsworth and Bell (1970) in their 
Strange Situation paradigm. In this paradigm, a mother brings her infant into a research room and allows the infant to play with toys. The mother then leaves the infant with a stranger in the room (separation). The stranger attempts to engage with the infant and then the mother returns (reunion). Based on their observations, during the Strange Situation paradigm, Ainsworth and Bell (1970) proposed three different attachment styles, one secure style and two insecure styles (anxious-resistant and anxious-avoidant). Infants with a secure attachment style were distressed upon separation and comforted upon reunion. Infants with an anxious-resistant attachment style were highly distressed upon separation and not able to be comforted upon reunion. Infants with an anxious-avoidant attachment style appeared indifferent upon both separation and reunion. Since Ainsworth and Bell's (1970) original study, there has been research indicating that there is a fourth infant attachment style, disorganized (Main \& Solomon, 1986). In contrast to the other styles of attachment, in which an infant has a consistent response to a caregiver, infants with a disorganized style do not maintain a consistent pattern of responses to their caregivers.

The style of attachment an infant develops is dependent upon how consistently the attachment figure meets the needs of the infant. If the infant's needs are consistently met, the infant will develop a secure attachment style (Ainsworth \& Bell, 1970). If the infant's needs are not consistently met, the infant will develop an insecure attachment style. Although we cannot claim direct causal relationships between attachment style and developmental outcomes, researchers have proposed that attachment begins a pathway promoting several developmental outcomes (Bowlby, 1973; Sroufe, 2005). Across development, children with insecure attachment styles have been found to be less self-reliant, have less capacity for emotion regulation, be less socially competent, and have a higher risk of developing psychopathologies than securely attached children (Sroufe, 2005). 
Infant attachment has also been linked to relationship qualities in adulthood (Bowlby, 1982; Bowbly, Bartholomew, 1990; Hazan \& Shaver, 1987; Waters, Weinfield, \& Hamilton, 2000). Hazan and Shaver (1987) examined adult romantic relationships from an attachment perspective. They translated the original three styles of infant attachment into three styles of adult romantic attachment. Other researchers have created models of adult attachment that include four attachment styles. Bartholomew (1990) conceptualized four styles of adult attachment. These styles were secure, preoccupied (anxious), dismissing (avoidant), and fearful (disorganized). The various attachment styles were consolidations of two dimensions:

representation of self and representation of others. A positive representation includes holding the beliefs that (a) you are worth having your needs met and that you are capable of meeting them and (b) others are capable and willing to meet your needs. A negative representation means holding the beliefs that (a) you are not worth having your needs met and that you are not capable of meeting them and (b) others are not capable and willing to meet your needs. Table 1 depicts the representations that make up each attachment style.

Table 1

Attachment Styles Based on Representations of Self and Others

\begin{tabular}{|c|c|c|c|}
\cline { 3 - 4 } \multicolumn{1}{c|}{} & \multicolumn{2}{c|}{ Representation of Self } \\
\cline { 3 - 4 } & Positive & Positive & Negative \\
\hline $\begin{array}{c}\text { Representation } \\
\text { of Others }\end{array}$ & Negative & $\begin{array}{c}\text { Dismissing } \\
\text { (avoidant) }\end{array}$ & $\begin{array}{c}\text { Preoccupied } \\
\text { (anxious) }\end{array}$ \\
\cline { 2 - 4 } & & Fearful \\
\hline
\end{tabular}


These differences in adult attachment style have been shown to be predictive of several factors. Research has found anxious attachment style to be predictive of remaining in an unfulfilling relationship (Slotter \& Finkel, 2009), greater incorporation of one's partner into one's self-concept (Slotter \& Gardner, 2011), experiencing aversive sexual affect and cognitions (Birnbaum, 2007), and lower relationship and sexual satisfaction (Birnbaum, 2007). Individual differences in attachment style have been shown to be predictive of differences in motives for sex. Schachner and Shaver (2004) found that anxiously attached participants reported engaging in sexual behaviors to create closeness with one's partner, feel valued, and reduce insecurity. Davis et al. (2004) found that attachment anxiety is not correlated to physical pleasure as a motive for sex but is positively correlated to emotional closeness, enhancing self-esteem, feeling partner's power, reassurance, stress reduction, feeling one's own power, manipulation, procreation, nurturing, and self-protection as motives for sex. Furthermore, individual differences in attachment style have been shown to be predictive of differences in motives for consenting to unwanted sex. Anxiously attached individuals report engaging in unwanted consensual sex due to fear that their partners would lose interest (Imett \& Peplau, 2002). Although, attachment anxiety has been directly linked with consenting to unwanted sex, perceived discrepancy between one's own commitment to a relationship and one's partner's commitment to the relationship has been shown to act as a mediating variable between both anxious and avoidant attachment and consenting to unwanted sex (Impett \& Peplau, 2003).

Avoidantly attached participants, on the other hand, reported engaging in sexual behaviors to impress their peers (Schachner \& Shaver 2004). Attachment avoidance was shown to be negatively associated with emotional closeness, reassurance, nurturance, and procreation as motives for sex. Attachment avoidance was positively associated with manipulation, feeling 
one's own power, stress reduction, and self-protection (Davis et al., 2004). Avoidantly attached individuals report engaging in unwanted consensual sex because they felt it was their obligation (Impett \& Peplau, 2003). So, although both anxious and avoidant attachment styles can lead to difficulties in sexual functioning, they have been found to lead to different types of difficulties in sexual functioning.

Another major factor that can be predicted from attachment style is rejection sensitivity. Drawing on social information-processing and attachment theory, Feldman and Downey (1994) conceptualized rejection sensitivity as the individual differences in how readily a person perceives and reacts to rejection as a result of early life experiences of rejection. Those with high rejection sensitivity have a greater tendency to perceive and react to rejection than those low in rejection sensitivity. Research has demonstrated that having an insecure attachment style is correlated with being higher in rejection sensitivity (Erozkan, 2009; Feldman \& Downey, 1994; Khoshkam et al., 2012). For example, Khoshkam et al. (2012) found an anxious attachment style to be correlated to rejection sensitivity, such that higher scores in attachment anxiety were associated with higher scores in rejection sensitivity. Feldman and Downey (1994) found that individuals with both avoidant and anxious attachment styles were higher in rejection sensitivity than those with secure attachment styles. Downey and Feldman (1996) examined rejection sensitivity in the context of interacting with a romantic partner. Romantic partners of target persons higher in rejection sensitivity reported more relationship dissatisfaction compared to romantic partners of target persons lower in rejection sensitivity. Specifically, partners reported this dissatisfaction to be due to the tendency of high rejection-sensitivity men to be jealous and controlling, and the tendency of high rejection-sensitivity women to be hostile and lacking in providing emotional support. Downey, Freitas, Michaelis, and Khouri (1998) expanded upon this 
direction of study by examining the self-fulfilling prophecy aspect of individuals with high rejection sensitivity in romantic relationships. Results revealed a pattern where when conflicts arose, women high in rejection sensitivity behaved in negative ways, which led to their partners responding with rejection, such as stating their dissatisfaction with the relationship and their thoughts of ending the relationship. Overall, relationships that included an individual high in rejection sensitivity were more likely to break up. Given that individuals with an insecure attachment style are more likely to experience rejection sensitivity, the present study examined more closely the relationship between CSA, attachment, and rejection sensitivity.

\section{Risk Recognition}

One explanation for the connection between CSA and later revictimization may be a deficit in risk recognition. Risk recognition can be defined as a person's ability to identify situations that may result in unwanted, dangerous, or violent outcomes. A common methodology for studying this phenomenon is using an audiotaped vignette depicting the escalation of sexual assault between a male and a female first developed by Marx and Gross (1995). Participants indicate when they believe the male in the vignette has "gone too far." Response latency is the time it takes a participant to decide that the man has "gone too far." Wilson et al. (1999) used this methodology to examine the relationships among trauma symptoms, risk recognition, and revictimization. Results showed that revictimized women had longer response latencies, or poorer risk recognition, than both nonvictims and single incident victims. This methodology is problematic, because it implies that risk recognition occurred before revictimization, but the study was not longitudinal. The current study did not examine revictimization for this reason.

Soler-Baillo, Marx, and Sloan (2005) used the same methodology but incorporated a physiological component. Consistent with past research, Soler-Baillo et al. (2005) found that 
victims of sexual abuse had larger response latencies, or poorer risk recognition, than nonvictims. Furthermore, nonvictims displayed greater heart rate reactivity (heart rate acceleration) in the early segments of the vignette than victims. The lack of heart rate reactivity in victims was seen as a physiological representation of poorer risk recognition. Melkonian et al. (2017) expanded upon prior research by including facial emotion interpretation in their study of risk recognition in sexual assault victims. Facial emotion interpretation refers to how accurately an individual infers another's emotions based on nonverbal facial expression. Following social information processing theory, interpreting the nonverbal facial emotions of others may be important for risk recognition of sexual assault. Facial emotion interpretation was measured by having participants label the emotions being expressed in a series of images of faces. Facial emotion interpretation moderated the relationship between victimization and risk recognition, such that having a history of sexual abuse was only correlated to risk recognition for those who performed poorer on the facial emotion interpretation task.

Some research suggests that CSA victims do not have lower levels of risk recognition but are simply less likely to respond to risky situations by leaving the situation. Vanzile-Tamsen et al. (2005) found that sexual assault history was not related to risk recognition but was related to lower levels of sexual refusal. Similarly, Naugle (1999) demonstrated that victims were just as likely to recognize risk but more likely to enter a situation with perceived risk. Meadows, Jaycox, Orsillo, and Foa (1997) found that victims were just as likely as nonvictims to recognize threat, but they had greater latency in indicating that they would leave a risky situation. Due to the inconsistency in research regarding whether risk recognition or risk response is driving the difference in adult victimization between victims of CSA and nonvictims, the current study viewed risk recognition as having two components—risk appraisal and risk response. Risk 
appraisal is whether an individual perceives a situation as risky. Risk response is whether an individual behaviorally removes themselves from the situation.

\section{The Current Study}

The purpose of the current study was to examine the possible relationships among history of CSA, insecure attachment style, rejection sensitivity, and risk recognition (risk appraisal and risk response). Examining these relationships may be important for gaining a better understanding of the link between CSA and revictimization in adulthood.

Research has shown that (a) victims of CSA often experience feelings of betrayal from someone they trusted and relied on (Finkelhor \& Browne, 1985), (b) individuals who have an insecure attachment style may be more likely to also have higher rejection sensitivity (Erozkan, 2009; Feldman \& Downey, 1994; Khoshkam et al., 2012), and (c) individuals with insecure attachment style and high rejection sensitivity may attempt to avoid rejection by pleasing their partners, including sexually (Imett \& Peplau, 2002). Research is inconsistent on whether victims of sexual abuse show deficits in appraising risk (Soler-Baillo et al., 2005; Wilson et al., 1999) or responding to risk (Meadows et al., 1997; Vanzile-Tamsen et al., 2005). Therefore, I proposed a mediation model and two moderation models. The proposed mediation model explored the relationships among CSA, attachment style, and rejection sensitivity (See figure 1.).

H1: Attachment anxiety and attachment avoidance would mediate the relationship between CSA and rejection sensitivity. Individuals with a history of CSA would have higher rejection sensitivity than those without a history of CSA. Individuals who experienced CSA would have higher attachment avoidance and attachment anxiety than those without a history of CSA. Attachment avoidance and attachment anxiety would be positively correlated with rejection sensitivity. 


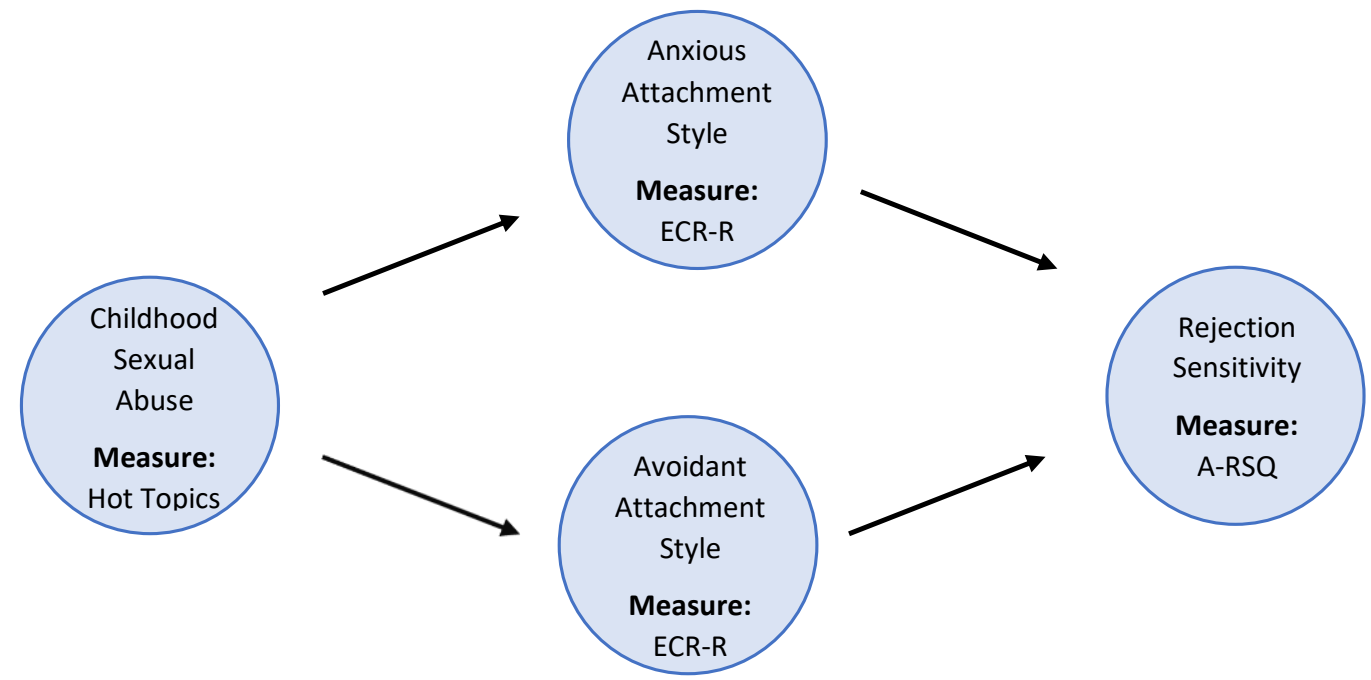

Figure 1. Hypothesized Mediation Model Connecting CSA and Rejection Sensitivity

The first proposed moderation model explored the relationship between rejection sensitivity, the rejection manipulation, and risk appraisal (See figure 2.). The second proposed moderation model explored the relationship between rejection sensitivity, the rejection manipulation, and risk response (See figure 3.).

$\mathrm{H} 2$ : Being exposed to rejection would moderate the relationship between rejection sensitivity and risk recognition (i.e., risk appraisal and risk response). When exposed to rejection, those with high rejection sensitivity would display greater latency of risk recognition (risk appraisal and risk response) than those low in rejection sensitivity. When not exposed to rejection, those high in rejection sensitivity would display greater latency, but not to the same degree as when exposed to rejection (See figure 4.). 


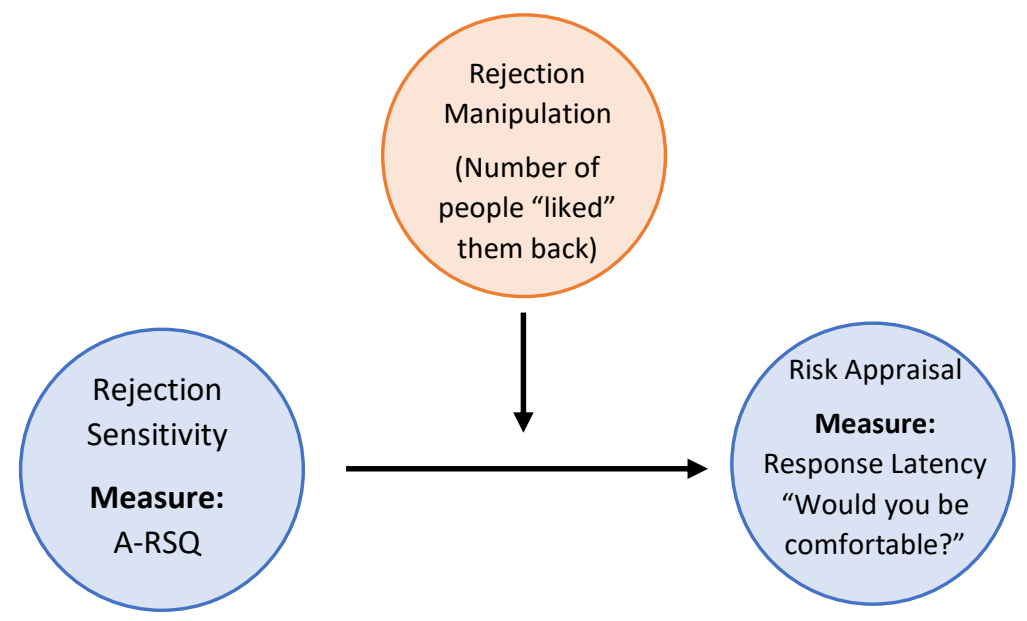

Figure 2. Hypothesized Moderation Model Connecting Rejection Sensitivity and Risk Appraisal

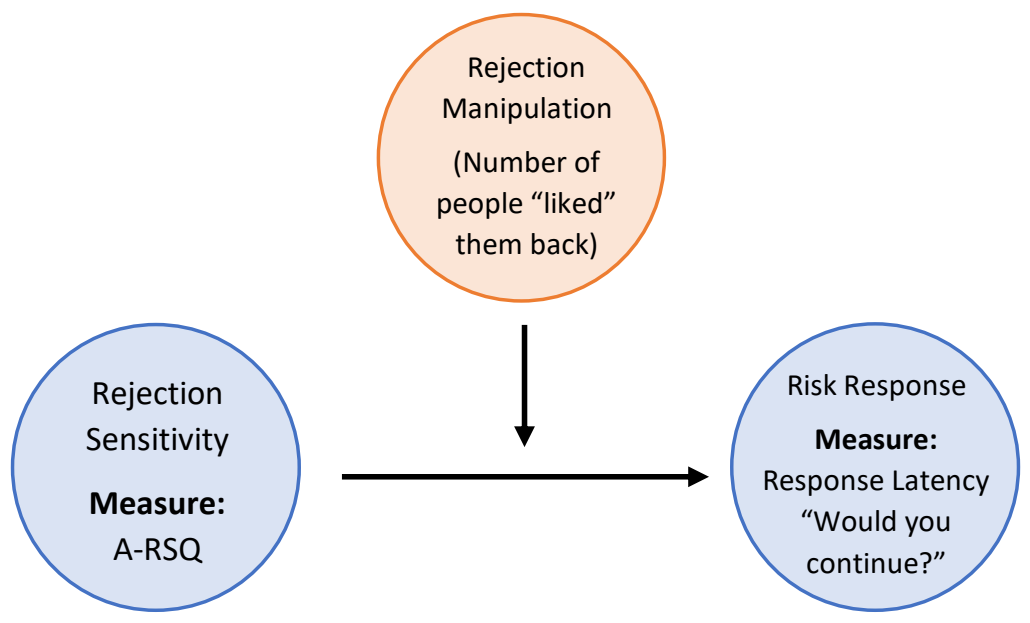

Figure 3. Hypothesized Moderation Model Connecting Rejection Sensitivity and Risk Response 


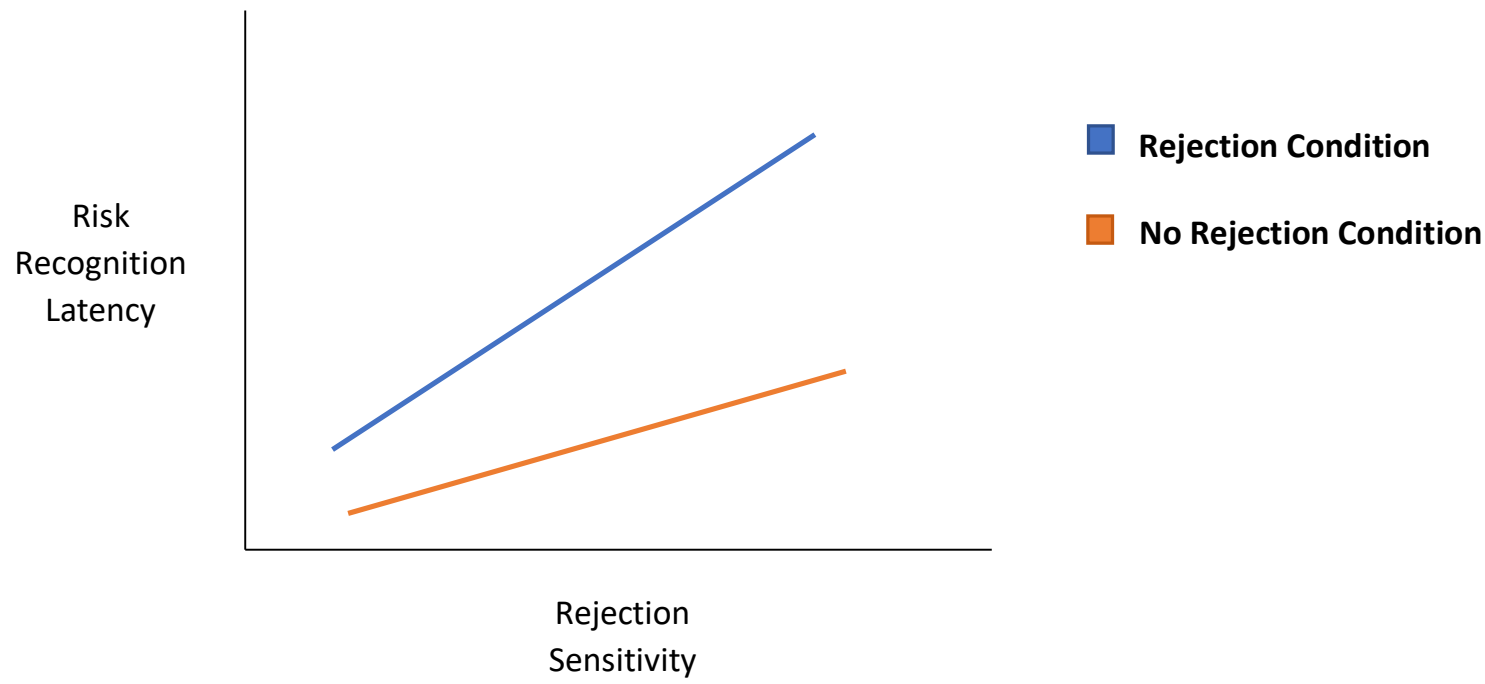

Figure 4. Hypothesized Risk Recognition Latency Relationships between Rejection Sensitivity and Rejection Manipulation for both Risk Appraisal and Risk Response 


\section{CHAPTER III: RESEARCH METHODOLOGY}

\section{Participants}

Participants for the current study consisted of undergraduate women attending Illinois State University between the ages of 18 to 22 years. This age range captures women at the stage of emerging adulthood, when revictimization is likely to occur (Reese-Weber \& Smith, 2011). In total, 236 participants completed the study. Of those, 13 cases were deleted due to a participant not following directions, participant not meeting inclusion requirements, or a procedural error. Therefore, the final sample consisted of 223 participants. Of these 223 participants, the mean age was 19.16 years $(S D=1.35)$. Within this sample more than half of the participants indicated that they did not have a history of CSA $(62.3 \%)$ and the remainder indicated that they did have a history of CSA (37.7\%). The majority of participants were White/Caucasian (67.3\%), followed by Black/African American (13.5\%), then Hispanic/Latino (13.0\%), and an equal number of participants identified as Asian-America (3.1\%) and Mixed Ethnicity (3.1\%). Most of the participants were freshmen $(52.0 \%)$, with the remaining being sophomores $(17.5 \%)$, juniors $(22.0 \%)$, and seniors $(8.5 \%)$. Just over half of the participants indicated they were single (55.6\%), which was followed by dating someone (39.9\%), then living with a significant other (3.6\%), and only 2 participants $(0.9 \%)$ indicated "other" as a relationship status. The majority of participants had parents who were currently married (63.2\%), with the remaining as follows: parents currently divorced (22.0\%), single parent (13.0\%), other (1.3\%), and one participant $(0.4 \%)$ did not answer this question. Nearly all participants were heterosexual (89.2\%), followed by bisexual $(6.3 \%)$, homosexual $(3.1 \%)$, pansexual $(0.9 \%)$, and other $(0.4 \%)$. With regard to mother's highest education, some participants indicated that their mother had some high school but no degree $(3.1 \%)$, others that their mother had a high school degree (26.5\%), 2 years of 
college (17.5\%), 4 years of college (33.2\%), and a graduate degree (19.7\%). With regard to father's highest education, some participants indicated that their father had some high school but no degree $(8.5 \%)$, others that their father had a high school degree (28.3\%), 2 years of college (15.2\%), 4 years of college (32.7\%), a graduate degree (14.8\%), and one participant $(0.4 \%)$ did not answer this question.

\section{Measures}

\section{Childhood Sexual Abuse}

The Hot Topics Survey (Reese-Weber \& Smith, 2011) was used to assess an individual's history of CSA. The Hot Topics Survey contains 15 items to which participants answer "yes" or "no." Five of the items assess CSA history, such that if participants answer "yes" to any of those five questions, they are considered in the CSA group. If participants answer "no" to all five of those questions, they are considered in the non-CSA group. The remaining 10 items are distractors asking about drug use and history of therapy. The five items of interest from the Hot Topics Survey were as follows: (1) "Before the age of 18, someone has sexually touched me in ways that made me feel uncomfortable," (2) "Before the age of 16, I had a sexual experience with an individual five or more years older than myself (any sexual activity involving physical contact)," (3) "Before the age of 18, another person has coerced me to engage in sexual activity (intercourse, oral sex, anal sex, petting/fondling)," (4) "Before the age of 18, I had engaged in sexual activity (intercourse, oral/anal sex, petting) when I didn't want to because someone threatened to use physical force," (5) "I have been sexual assaulted before the age of 18."

If a participant responded in a way that indicated a history of CSA on the Hot Topics Survey, they completed the Childhood Sexual Abuse Questionnaire (Finkelhor, 1979) as a follow-up measure. This questionnaire includes 10 items inquiring about the nature of the abuse, 
including victim and abuser age, relationship to abuser, use of threat, specific sexual acts, and disclosure of the abuse.

\section{Adult Attachment Style}

The Experiences in Close Relationships-Revised (ECR-R) questionnaire was used to assess participants' levels of attachment anxiety and attachment avoidance (Fraley, Waller, \& Brennan, 2000). The ECR-R is a revised version of the ECR created by Brennan, Clark, and Shaver (1998). The ECR-R contains 36 items to which participants rate their agreement or disagreement on a 7-point Likert scale, ranging from 1 (Strongly Disagree) to 7 (Strongly Agree). An example of an item from the ECR-R assessing attachment anxiety is "I often worry that my partner does not really love me." An example of an item from the ECR-R assessing attachment avoidance is "I get uncomfortable when a romantic partner wants to be very close." Fraley et al. (2000) found both the results of the anxious and avoidance scales to have Cronbach's alpha reliabilities of .81 . In the present study, the scores of the anxious scale were found to have a Cronbach's alpha of .82, and the scores of the avoidance scale were found to have a Cronbach's alpha of 94.

\section{Rejection Sensitivity}

The Rejection Sensitivity Questionnaire, Adult version (A-RSQ) (Berenson et al., 2009) is an adaptation of the original Rejection Sensitivity Questionnaire (RSQ) (Downey \& Feldman, 1996). The A-RSQ was used to assess how readily participants perceive rejection. Nine items were used to assess rejection sensitivity. Participants responded to each item in two parts. In the original survey, they indicated how concerned they would be on a 6-point scale ranging from 1 (very unconcerned) to 6 (very concerned), and they indicated the extent they would expect to be rejected in the situation on a 6-point scale ranging from 1 (very unlikely) to 6 (very likely). 
However, due to an error in creating our measure, these items were ranked on a 7-point scale. An example of an item from the A-RSQ is "You ask your parents or another family member for a loan to help you through a difficult financial time. How concerned or anxious would you be over whether or not your family would want to help you (very unconcerned to very concerned)? I would expect that they would agree to help as much as they can (very unlikely to very likely)." Indicating greater concern and higher likeliness of rejection was indicative of higher rejection sensitivity. The A-RSQ had a .87 correlation to the original RSQ. Rejection sensitivity scores of the A-RSQ had a coefficient alpha of .74. Furthermore, the A-RSQ has been shown to have good discriminant validity and captures individual differences across groups of adults. Berenson et al. (2009) found scores of the A-RSQ to have a Cronbach's alpha of .86. The scores from the current study had a Cronbach's alpha of .72. However, looking at the two types of questions individually, the Cronbach's alpha for scores from part one (level of concern) was .85, and the Cronbach's alpha for scores from part two (expectation of rejection) was .91.

\section{Rejection Manipulation}

To evoke feelings of rejection participants reviewed 10 researcher-created profiles of men, and they chose the top 5 who they would be interested in messaging or meeting. Participants then completed a brief profile for an online dating site, which consisted of up to 500 characters stating whatever participants would want potential dating partners to know about them. The rejection manipulation included informing participants that, based on the new algorithm we were working on and the profile they created, 8 of the men whose profiles they viewed ( 4 who they indicated interest in) were selected as compatible for them (no rejection condition), or that 2 of the men whose profiles they viewed ( 1 who they indicated interest in) were selected as compatible for them (rejection condition). A manipulation check was done by 
verbally asking all participants on a scale from 0 (not at all rejected) to 5 (completely rejected) how rejected they felt when they were informed about their number of matches. A $t$-test was conducted to check the rejection manipulation. The $t$-test revealed that the 112 participants in the rejection condition $(M=0.99, S D=1.21)$ and the 110 participants in the non-rejection condition $(M=0.35, S D=0.77)$ demonstrated a significant difference in rejection rating, $t(31.56)=-4.66$, $p=<.001$; as expected, those in the rejection condition rated their feelings of rejection as higher than those in the non-rejection condition.

\section{Risk Recognition (Risk Appraisal and Risk Response)}

Participants read through a vignette, created for this study, of a man and women messaging via an online dating app; see Appendix A. The vignette was designed based on similar previously written vignettes, (Abbey, Buck, Zawacki, \& Saenz, 2003; Soler-Baillo et al., 2005; Vanzile-Tamsen et al., 2005). The vignette was divided into 13 scenes. At the end of each scene participants were asked two questions, one to assess risk appraisal ("Would you feel comfortable in this situation?") and one to assess risk response (“Would you continue this interaction?"). The further into the vignette a participant continued to answer "yes" to the risk appraisal question, the poorer the participant's risk appraisal. The further into the vignette a participant continued to answer "yes" to the risk response question, the poorer the participant's risk response. When a participant answered "no" to both questions, the vignette stopped.

\section{Procedure}

Participants were recruited using the online psychology participant pool (SONA). Participants interested in participating arrived individually to a research lab and met with a research assistant. First, participants were asked to provide informed consent. This study included deception such that participants were told that the study was examining a new algorithm 
for an online dating application. Once consent was indicated, the participants completed the study measures via an online survey administered through Qualtrics. The surveys were in the order of demographics, Personality Inventory for DSM-5-Brief Form, A-RSQ, Hot Topics Survey, Child Sexual Abuse Questionnaire (if indicated CSA on Hot Topics Survey), ECR-R, and Big Five Inventory. The current study was part of a larger study, and the data from the Personality Inventory for DSM-5-Brief Form and the Big Five Inventory were not used in the current study. Then participants viewed the researcher-created profiles and created their own profile. Participants were then told their number of matches based on the manipulation group. Next participants read and completed the risk recognition vignette. After completing the vignette, participants were debriefed on the study, which included being told that the online dating application was not the purpose of the study and that the number of matches were used as a manipulation to invoke a sense of rejection. Then participants were verbally asked to rate their feelings of rejection when they heard about their number of matches. 


\section{CHAPTER IV: RESULTS}

Preliminary analysis revealed that $37.7 \%$ of participants reported having experienced CSA and $62.3 \%$ of participants reported not having experienced CSA. Preliminary correlations were also conducted to examine the relationships between all variables. Correlations are displayed in Table 2 .

Table 2

Correlations, Means, and Standard Deviations among Person-level Measures $(N=223)$

\begin{tabular}{lllllllll}
\hline Measure & 1 & 2 & 3 & 4 & 5 & 6 & 7 & 8 \\
\hline 1. CSA & -- & & & & & & & \\
2. Attachment Anxiety & $.16^{*}$ & -- & & & & & & \\
3. Attachment Avoidance & .11 & $.49^{*}$ & -- & & & & & \\
4. Rejection Sensitivity & .07 & $.22^{*}$ & .12 & -- & & & & \\
5. Rejection Manipulation & -.08 & -.06 & -.02 & -.05 & -- & & & \\
6. Rejection Rating & $-.16^{*}$ & .04 & .00 & -.12 & $.30^{*}$ & -- & & \\
7. Risk Appraisal & -.08 & .05 & .01 & .00 & .04 & $.16^{*}$ & -- & \\
8. Risk Response & -.01 & .06 & .05 & .02 & .06 & $.17^{*}$ & .80 & -- \\
& & & & & & & & \\
$M$ & .38 & 64.09 & 48.76 & 17.47 & .50 & .68 & 3.15 & 3.22 \\
SD & .49 & 22.81 & 19.98 & 7.89 & .50 & 1.07 & 1.45 & 1.61 \\
& & & & & & & & \\
\hline Note. CSA was coded $0=$ no history of CSA and 1 1 history of CSA & & & & & &
\end{tabular}

Hypothesis 1 stated that attachment anxiety and attachment avoidance would mediate the relationship between CSA and rejection sensitivity, such that those with a history of CSA would have higher rejection sensitivity than those without a history of CSA, those who experienced CSA would have higher attachment avoidance and attachment anxiety than those without a history of CSA, and attachment avoidance and attachment anxiety would be positively correlated 
with rejection sensitivity. A parallel multiple mediation analysis using PROCESS was conducted to test this hypothesis. This analysis had two parts. The first was a series of regression analyses, finding a slope for each arrow in the model, revealing the direct effects. The second part was to determine if the indirect effects were significant. This is done using a process called bootstrapping, which provided a confidence interval of indirect effects (Hayes, 2009). Bootstrapping is a process where random samples are drawn from a population pool. This is done with continuous replacement, so after each draw the selection is placed back into the pool and has the same chance of being drawn out again. Therefore, bootstrapping creates a sample where some members of the original pool are repeated, and some are absent (Mallinckrodt et al., 2006). Results indicated that there was a significant direct relationship between CSA and anxious attachment, $b=7.91, p<.001$. There was also a significant direct relationship between anxious attachment and rejection sensitivity, $b=0.07, p=.01$ (See figure 5.). There was not a significant direct relationship between CSA and avoidant attachment, $b=4.65, p=.09$, between CSA and rejection sensitivity, $b=0.54, p=.612$, or between avoidant attachment and rejection sensitivity, $b=0.01, p=.85$. There was no significant mediation of the relationship between CSA and rejection sensitivity by avoidant attachment, indirect effect $=.03, \mathrm{CI}=(-0.30,0.41)$. However, there was a significant mediation of the relationship between CSA and rejection sensitivity by anxious attachment, indirect effect $=0.67, \mathrm{CI}=(0.07,1.29)$. Thus, Hypothesis 1 was partially supported. 


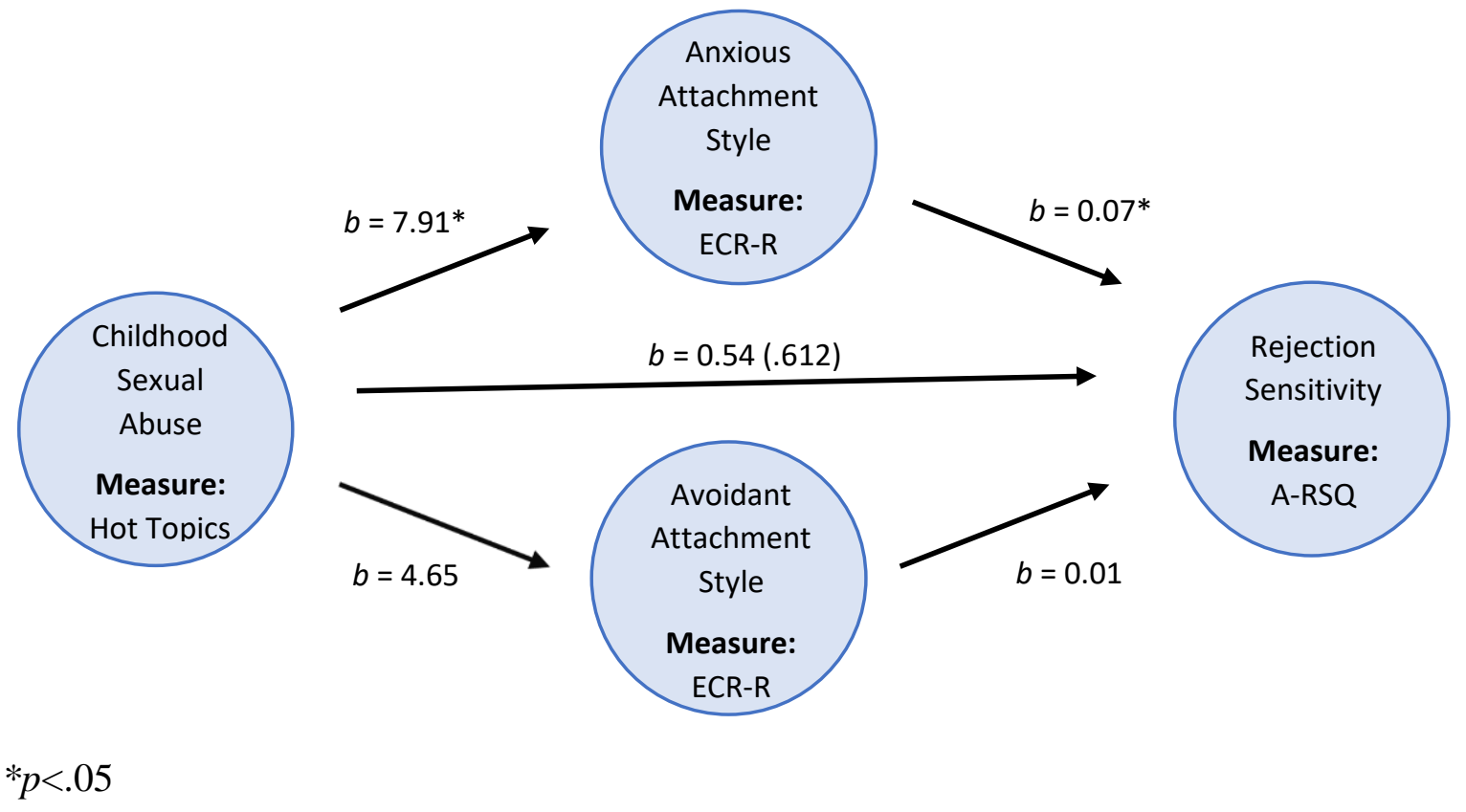

Figure 5. Hypothesis 1 Mediation Model Connecting CSA and Rejection Sensitivity Results

Hypothesis 2 stated that being exposed to rejection would moderate the relationship between rejection sensitivity and risk recognition, such that when exposed to rejection, those with high rejection sensitivity would display greater latency of risk recognition (risk appraisal and risk response) than those low in rejection sensitivity, and not exposed to rejection, those high in rejection sensitivity would display greater latency, but not to the same degree as when exposed to rejection. A moderation analysis using PROCESS was conducted to test this hypothesis. Essentially, what was calculated was a regression analysis with three variables. The variables were rejection sensitivity, rejection manipulation, and the interaction between rejection sensitivity and rejection manipulation (i.e., the product of the two variable).

Results indicated that there was no significant relationship between rejection sensitivity and risk appraisal, $b=0.00 p=.96$, nor was there a significant relationship between the rejection manipulation and risk appraisal, $b=0.09, p=.65$. Furthermore, the rejection manipulation did 
not significantly moderate the relationship between rejection sensitivity and risk appraisal, $b=$ $0.00, \Delta R^{2}=.00, F(1,217)=0.03, p=.86$. Results also indicated that there was no significant slope between rejection sensitivity and risk response, $b=0.01, p=.73$, nor was there a significant slope between the rejection manipulation and risk response, $b=0.19, p=.38$. Furthermore, the rejection manipulation did not significantly moderate the slope between rejection sensitivity and risk response, $b=-0.02, \Delta R^{2}=.00, F(1,217)=0.63, p=.43$. Thus, Hypothesis 2 was not supported. Slopes and standard errors are displayed in Table 3.

Table 3

Multiple Regression Analyses Predicting Risk Recognition from Rejection Sensitivity, Rejection Manipulation, and the Interaction between Rejection Sensitivity and Rejection Manipulation

\begin{tabular}{llcc}
\hline Model & Predictor & $b$ & $S E$ \\
\hline Risk Appraisal & Rejection Sensitivity & 0.00 & 0.02 \\
& Rejection Manipulation & 0.01 & 0.48 \\
& $\begin{array}{l}\text { Rejection Sensitivity x Rejection } \\
\text { Manipulation }\end{array}$ & 0.00 & 0.03 \\
Risk Response & Rejection Sensitivity & 0.01 & 0.02 \\
& Rejection Manipulation & 0.58 & 0.53 \\
& $\begin{array}{l}\text { Rejection Sensitivity x Rejection } \\
\text { Manipulation }\end{array}$ & -0.02 & 0.03 \\
\hline
\end{tabular}

Note. Rejection Manipulation was coded $0=$ non-rejection and $1=$ rejection. 


\section{CHAPTER V: DISCUSSION}

CSA is a common issue in society, with previous research showing that approximately one in four women experience CSA (Finkelhor et al., 2014). The current study suggests that this number may be even larger, with almost $40 \%$ of the participants reporting a history of CSA. Previous research suggests that a history of CSA is related to having a more insecure attachment style (Roche et al, 1999) and having poorer risk recognition (Soler-Baillo et al., 2005). The present study did not find a significant relationship between CSA and risk recognition. Results of the present study do, however, suggest a significant relationship between CSA and anxious attachment. Results also suggest that there is a significant relationship between anxious attachment and rejection sensitivity. Furthermore, results suggest that anxious attachment mediates the relationship between CSA and rejection sensitivity.

Hypothesis 1 stated that anxious and avoidant attachment would mediate the relationship between CSA and rejection sensitivity. This hypothesis was partially supported. Consistent with

previous research (Erozkan, 2009; Roche et al, 1999), those with a history of CSA were higher in attachment anxiety. Furthermore, those who were higher in attachment anxiety were higher in rejection sensitivity.

Inconsistent with previous research (Bifulco et al., 2006, Feldman \& Downey, 1994), there were no direct or indirect relationships between CSA, avoidant attachment, and rejection sensitivity. This contradictory finding could be due to differences in methodology. For example, Bifulco et al. (2006) did not examine sexual abuse alone, but rather examined sexual abuse, physical abuse, and neglect together.

Another explanation for the significant relationship between CSA and anxious attachment but not avoidant attachment could be the notion of powerlessness. Finkelhor and Browne's 
(1985) traumagenic dynamics model emphasizes that victims of CSA often experience feelings of powerlessness. Individuals high in anxious attachment have a negative representation of self and a positive representation of others (Bartholomew, 1990); therefore, they tend to feel that they do not have power and control but that others do have power and control. Those high in avoidant attachment, on the other hand, have a positive representation of self and a negative representation of others (Bartholomew, 1990); therefore, they are more likely to view themselves as having power and control. So, it would make sense for feelings of powerlessness to develop into anxious attachment rather than avoidant attachment.

Bartholomew's (1990) model of self and other representations could also explain the lack of relationship found between avoidant attachment and rejection sensitivity. Those high in anxious attachment have a positive representation of others and would likely hold the opinions of others in high regard, therefore, being more likely to have strong reactions to rejection by others. Those high in avoidant attachment, on the other hand, have a negative representation of others and would likely not hold the opinions of others in high regard, therefore, being less likely to have strong reactions to rejection by others.

In addition, the current study may not have found a relationship between avoidant attachment and rejection because of the use of self-report surveys. Those high in avoidant attachment tend to avoid their feelings and avoid relying on others. Therefore, it is expected that, those high in avoidant attachment would not self-report feelings of rejection, and potentially not even recognize these feelings within themselves, even if these feelings were experienced.

Hypothesis 2 stated that experiencing rejection (via the rejection manipulation) would moderate the relationship between rejection sensitivity and risk recognition. Although this section of the study was novel, it was believed that those high in rejection sensitivity would be 
more likely to engage in non-consensual sexual behaviors to avoid feelings of rejection, therefore promoting poorer risk recognition. This hypothesis was not supported. There was no direct or moderated relationship between rejection sensitivity and risk appraisal or between rejection sensitivity and risk response. These results are inconsistent with what was expected based on the previous literature used to form Hypothesis 2 that suggests that individuals who have a history of CSA show greater latencies in risk appraisal (Wilson et al., 1999) and risk response (VanzileTamsen et al., 2005).

Perhaps a relationship was not found between the rejection manipulation and risk recognition because the rejection manipulation was not strong enough. Although those in the rejection condition did report significantly greater feelings of rejection than those in the nonrejection condition, feelings of rejection scores tended to be toward the low end of the scale in both conditions. Perhaps the rejection manipulation would need to be more intense to evoke feelings of rejection strong enough to influence risk recognition. This could potentially be done by including pictures in the profiles the participants view and having participants include their own picture in the profile they create. This manipulation would also more accurately replicate dating sites, which often include pictures.

It is also possible that limiting participants to yes-or-no responses did not pick up more subtle variations in risk recognition. Perhaps if risk appraisal and risk response had been measured using a Likert-scale at the end of each scene instead of yes-or-no questions a relationship would have been found between the rejection manipulation and risk recognition.

Although a direct relationship between CSA and risk recognition was not hypothesized in the current study, this is the relationship that has been examined in previous literature and was used to form Hypothesis 2. So, correlation analyses, displayed in Table 2, were conducted in the 
current study to see if there were relationships between CSA, risk appraisal, and risk response. Results showed neither risk appraisal nor risk response to be related to CSA. This is inconsistent with previous research and may be due to differences in methodology. Vignettes used to measure risk recognition vary greatly across studies. Some studies use audiotaped vignettes (Marx \& Gross, 1995), while others use written vignettes (Vanzile-Tamsen et al., 2005). Some studies measure risk recognition in latency in seconds (Soler-Baillo et al., 2005), while others measure risk recognition in overall Likert-scale scores (Melkonian et al., 2017). Methodology needs more standardization to be more comparable across studies. Although the current study created the risk recognition vignette used based on other studies, validity of the measure cannot be confirmed at this time. Either longitudinal studies tracking revictimization or studies focusing on participants rating the risk of each scene to get a sense of generally agreed upon levels of risk are needed to confirm the validity of the vignette.

\section{Limitations and Future Directions}

A limitation of this study was that it did not consider differences in aspects of CSA history or healing support and resources among victims, such as frequency of abuse, relationship to the abuser, and access to post-abuse resources. This information would be valuable to consider because research has shown that factors such as relationship to the perpetrator, intensity of abuse, and the use of force are associated with differences in severity of outcomes (Tyler, 2002). Repetitive abuse has been linked to worse outcomes, and the perpetrator being a family member has been associated with more internalization in victims (Mian et al., 1996). The use of force by the perpetrator has been shown to correlate with greater severity of outcome symptoms (Mennen $\&$ Meadow, 1995). Protective factors, such as parental support, have been shown to be related to more positive outcomes for victims, including fewer externalizing behaviors (Tremblay et al., 
1999). It is possible that factors such as repetitive abuse, being related to the perpetrator, and the use of force would be associated with poorer risk recognition, while protective factors, such as parental support, would be associated with better risk recognition. These differing aspects of CSA history among victims would be valuable factors to consider in future studies.

Given that prevalence rates indicate that CSA occurs most frequently to women (Finkelhor et al., 2014) and that sexual assault is a common problem on college campuses (Fedina, Holmes, \& Backes, 2016), the current study used a sample population of undergraduate women; however, this limits the generalizability of the results. Other populations, males and non-college students, can also be victims of abuse and may respond in different ways. For example, studies have shown men to be higher in avoidant attachment and lower in anxious attachment than women (Del Giudice, 2010). Given the results of the current study suggesting that anxious, but not avoidant, attachment is related to rejection sensitivity, perhaps men would be less likely than women to be high in rejection sensitivity. If this were the case, then interventions designed to target rejection sensitivity in CSA victims may be more effective for female populations.

Another limitation was the inclusion of non-heterosexual females in a study that was oriented toward heterosexual individuals. The researcher-created profiles were all men, and the vignette depicted a scenario between a man and a woman. Given the prevalence rates of male perpetrators to female victims (Finkelhor, 1994), it was logical to design the study to be oriented toward heterosexual females. However, although all participants were asked to imagine that they were a heterosexual female interested in dating, it is possible that it was more difficult for nonheterosexual participants to imagine this. In future studies focusing on heterosexual individuals, it would be beneficial to exclude non-heterosexual participants from data analysis. It would also 
be beneficial to design variations of the study oriented toward other populations, including nonheterosexual females.

\section{Strengths and Conclusions}

The current study contributed to the literature on sexual abuse by providing additional information on the relationships among CSA, attachment, rejection sensitivity, and risk recognition. This is the first time these factors have been examined in combination. This study also attended to the differences in definition of the term "risk recognition," illuminating both risk appraisal and risk response. Although a relationship between CSA and risk recognition was not found, further evidence was found supporting the relationships between CSA, anxious attachment, and rejection sensitivity. These may serve as areas for practitioners to target when working with victims of CSA. When working with victims of CSA, practitioners should make sure to attend to signs of anxious attachment, as they are indicators of high rejection sensitivity. For example, if a clinician were able to identify that a client is struggling with high rejection sensitivity, they may want to consider involving them in group therapy situations where clients can experience rejection in a safe manner and thereby grow more comfortable with feelings of rejection as well as fact check with others to see if perceived rejection is accurate (Yalom \& Leszcz, 2008). Clinicians may also want to use strategies designed to target anxious attachment, such as Dialectic Behavior Therapy, which is an intervention designed for group settings, but can be done individually, that teaches distress tolerance, emotion regulation, mindfulness, and interpersonal effectiveness skills (Linehan, 2015).

Despite the low variation in feelings of rejection, a strength of the study is that the rejection manipulation did work, and those in the rejection condition reported significantly greater feelings of rejection than those in the non-rejection condition. This was the first time a 
manipulation like this was used in this area of research. Going forward, researchers should take the information illuminated regarding the present study's rejection manipulation and use it to guide the design of similar rejection manipulations. This could entail implementing a more intense rejection manipulation, thereby, potentially eliciting responses not seen in the less intense manipulation used in the current study. Additionally, this study brought previous vignettes designed to examine risk recognition into an online dating format. This was the first time that commonly used vignettes, such as the vignette created by Marx and Gross (1995), were brought into an online dating format. This novel study will be able to guide future research in a direction that is applicable to society's changing dating environment. Society is shifting more and more toward online dating. Hogan, Dutton, and Li (2011) found that over one-third of their sample had tried online dating at least once. Online dating comes with its own set of factors that influence risk recognition, such as increased opportunities for deception, with estimates of one-third of online dating site users engaging in deception (Caspi \& Gorsky, 2006). Future studies would benefit from following the precedent set in the present study of keeping up with current dating trends and the popular shift to an online dating format. 


\section{REFERENCES}

Ainsworth, M. D. S., \& Bell, S. M. (1970). Attachment, exploration, and separation: Illustrated by the behavior of one-year-olds in a strange situation. Child Development, 41, 49-67. doi:10.2307/1127388

Arnett, J. J. (2000). Emerging adulthood: A theory of development from the late teens through the twenties. American Psychologist, 55, 469-480. doi:10.1037/0003-066X.55.5.469

Arriola, K. R. J., Louden, T., Doldren, M. A., \& Fortenberry, R. M. (2005). A meta-analysis of the relationship of child sexual abuse to HIV risk behavior among women. Child Abuse \& Neglect, 29, 725-746. doi:10.1016/j.chiabu.2004.10.014

Barnes, J. E., Noll, J. G., Putnam, F. W., \& Trickett, P. K. (2009). Sexual and physical revictimization among victims of severe childhood sexual abuse. Child Abuse \& Neglect, 33, 412-420. doi:10.1016/j.chiabu.2008.09.013

Bartholomew, K. (1990). Avoidance of intimacy: An attachment perspective. Journal of Social and Personal Relationships, 7, 147-178. doi:10.1177/0265407590072001

Berenson, K. R., Gyurak A., Ayduk, O., Downey G., Garner, M. J., Mogg, K. Bradley, B. P., \& Pine, D. S. (2009). Rejection sensitivity and disruption of attention by social threat cues. Journal of Research in Personality, 43, 1064-1072. doi:10.1016/j.jrp.2009.07.007

Bergen, H. A., Martin, G., Richardson, A.S., Allison, S., \& Roeger, L. (2004). Sexual abuse, antisocial behavior and substance use: gender differences in young community adolescents. Australian and New Zealand Journal of Psychiatry, 38, 34-41. doi:10.1111/j.1440-1614.2004.01295.x 
Bifulco, A., Kwon, J., Jacobs, C., Moran, P. M., Bunn, A., \& Beer, N. (2006). Adult attachment style as a mediator between childhood neglect/abuse and adult depression and anxiety. Social Psychiatry and Psychiatric Epidemiology, 41, 796-805. doi:10.1007/s00127-006-0101-z

Birnbaum, G. E. (2007). Attachment orientations, sexual functioning, and relationship satisfaction in a community sample of women. Journal of Social and Personal Relationships, 24, 21-35. doi:10.1177/0265407507072576

Bowlby, J. (1982). Attachment. (Attachment and loss: Volume I). (2nd ed.). New York: Basic Books.

Bowlby, J. (1973). Attachment and loss. Vol. 2: Separation: Anxiety and anger. New York: Basic Books.

Brennan, K. A., Clark, C. L., \& Shaver, P. R. (1998). Self-report measurement of adult attachment: An integrative overview. In J. A. Simpson \& W. S. Rholes (Eds.), Attachment theory and close relationships (pp. 46-76). New York: Guilford.

Caspi, A., \& Gorsky, P. (2006). Online deception: Prevalence, motivation, and emotion. CyberPsychology \& Behavior, 9, 54-62. doi:10.1089/cpb.2006.9.54

Conley, A. H., Overstreet, C. M., Hawn, S. E., Kendler, K. S., Dick, D. M., \& Amstadter, A. B. (2017). Prevalence and predictors of sexual assault among a college sample. Journal of American College Health, 65, 41-49. doi:10.1080/07448481.2016.1235578

Croysdale, A. E., Drerup, L. C., Bewsey, K., \& Hoffmann, N. G. (2008). Correlates of victimization in a juvenile justice population. Journal of Aggression, Maltreatment \& Trauma, 17, 103-117. doi:10.1080/10926770802250876 
Davis, D., Shaver, P. R., \& Verson, M. L. (2004). Attachment style and subjective motivations for sex. PSPB, 30, 1076-1090. doi:10.1177/0146167204264794

Del Giudice, M. (2010). Sex differences in romantic attachment: A meta-analysis. Personality and Social Psychology Bulletin, 37, 193-214. doi:10.1177/0146167210392789

Downey, G., \& Feldman, S. I. (1996). Implications of rejection sensitivity for intimate relationships. Journal of Personality and Social Psychology, 6, 1327-1343. doi:10.1037/0022-3514.70.6.1327

Downey, G., Freitas, A. L., Michaelis, B., \& Khouri, H. (1998). The self-fulfilling prophecy in close relationships: Rejection sensitivity and rejection by romantic partners. Journal of Personality and Social Psychology, 75, 545-560. doi:10.1037/0022-3514.75.2.545

Erozkan, A. (2009). Rejection sensitivity levels with respect to attachment styles, gender, and parenting styles: A study with Turkish students. Social Behavior and Personality, 37, 1-14. doi:10.2224/sbp.2009.37.1.1

Fedina, L., Holmes, J. L., \& Backes, B. L. (2016) Campus sexual assault: A systematic review of prevalence research from 2000 to 2015. Trauma, Violence, and Abuse, 19, 76-93. doi:10.1177/1524838016631129

Feiring, C., Miller-Johnson, S., \& Cleland, C. M. (2007). Potential pathways from stigmatization and internalizing symptoms to delinquency in sexually abused youth. Child Maltreatment, 12, 220-232. doi:10.1177/1077559507301840

Feldman, S., \& Downey, G. (1994). Rejection sensitivity as a mediator of the impact of childhood exposure to family violence on adult attachment behavior. Development and Psychopathology, 6, 231-247. doi:10.1017/S0954579400005976 
Fergusson, D. M., Boden, J. M., \& Horwood, L. J. (2008). Exposure to childhood sexual and physical abuse and adjustment in early adulthood. Child Abuse \& Neglect, 32, 607619. doi:10.1016/j.chiabu.2006.12.018

Fergusson, D. M, McLeod, F. H., \& Horwood, J. (2013). Childhood sexual abuse and adult developmental outcomes: Findings from a 30-year longitudinal study in New Zealand. Child Abuse \& Neglect, 37, 664-674. doi:10.1016/j.chiabu.2013.03.013

Filipas, H. H., \& Ullman, S. E. (2006). Child sexual abuse, coping responses, self-blame, posttraumatic stress disorder and adult sexual revictimization. Journal of Interpersonal Violence, 21, 652-672. doi:10.1177/0886260506286879

Finkelhor, D. (1979). Sexually victimized children. New York: Free Press.

Finkelhor, D. (1994). Current information on the scope and nature of childhood sexual abuse. The future of children, 4, 31-53.

Finkelhor, \& Browne (1985). The traumatic impact of child sexual abuse: A conceptualization. American Journal of Orthopsychiatry, 55, 530-541. doi:10.1111/j.1939-0025.1985.tb02703.x

Finkelhor, D., Shattuck, A., Turner, H. A., \& Hamby, S. L. (2014). The lifetime prevalence of child sexual abuse and sexual assault assessed in late adolescence. Journal of Adolescent Health, 55, 1-5. doi:10.1016/j.jadohealth.2013.12.026

Fraley, R. C., Waller, N. G., \& Brennan, K. A. (2000). An item-response theory analysis of selfreport measures of adult attachment. Journal of Personality and Social Psychology, 78, 350-365. doi:10.1037/0022-3514.78.2.350 
Hayes, A. F. (2009). Beyond Baron and Kenny: Statistical mediation analysis in the new millennium. Communication Monographs, 76, 408-420. doi:10.1080/03637750903310360

Hazan, C., \& Shaver, P. (1987). Romantic love conceptualized as an attachment process. Journal of Personality and Social Psychology, 52, 511-524.

Hogan, B., Dutton, W., \& Li, N. (2011). A global shift in the social relationships of networked individuals: Meeting and dating online comes of age. Me, My Spouse and the Internet Project. Oxford Internet Institute. doi:10.2139/ssrn.1763884

Homma, Y., Wang, N., Saewyc, E., \& Kishor, N. (2012). The relationship between sexual abuse and risky sexual behavior among adolescent boys: A meta-analysis. The Journal of Adolescent Health, 51, 18-24. doi:10.1016/j.jadohealth.2011.12.032

Gladstone, G. J., Parker, G. B., Mitchell, P. B., Malhi, G. S., Wilhelm, K., \& Austin, M. (2004). Implications of childhood trauma for depressed women: An analysis of pathways from childhood sexual abuse to deliberate self-harm and revictimization. The American Journal of Psychiatry, 161, 1417-1425. doi:10.1176/appi.ajp.161.8.1417

Impett, E. A., \& Peplau, L. A. (2003). Why some women consent to unwanted sex with a dating partner: Insights from attachment theory. Psychology of Women Quarterly, 26, 360-370. doi:10.1111/1471-6402.t01-1-00075

Khoshkam, S., Bahrami, F., Ahmadi, S. A., Fatehizade, M., \& Etemadi, O. (2012). Attachment style and rejection sensitivity: The mediating effect of self-esteem and worry among Iranian college students. Europe's Journal of Psychology, 8, 363-374. doi:10.5964/ejop.v8i3.463

Linehan, M. M. (2015). DBT® skills training manual (2nd ed.). New York: Guilford Press. 
Main, M., \& Solomon, J. (1986). Discovery of an insecure-disorganized/disoriented attachment pattern. In T. B. Brazelton \& M. W. Yogman (Eds.), Affective development in infancy (pp. 95-124). Westport, CT: Ablex Publishing.

Mallinckrodt, B., Abraham, T. W., Wei, M., \& Russell, D. W. (2006). Advances in testing the statistical significance of mediation effects. Journal of Counseling Psychology, 53, 372-378. doi:10.1037/0022-0167.53.3.372

Marx, B. P., \& Gross, A. M. (1995). Date rape: An analysis of two contextual variables. Behavior Modification, 19, 451-463. doi:10.1177/01454455950194003

Meadows, E. A., Jaycox, L. H., Orsillo, S. M., \& Foa, E. B. (1997, November). The impact of assault on risk recognition in ambiguous situations. Paper presented at the 29th Annual Meeting of the Association for the Advancement of Behavior Therapy, Washington, DC.

Melkonian, A. J., Ham, L. S., Bridges, A. J., \& Fugitt, J. L. (2017). Facial emotion identification and sexual assault risk detection among college student sexual assault victims and nonvictims. Journal of American College Health, 65, 466-473. doi:10.1080/07448481.2017.1341897

Mennen, F. E., \& Meadow, D. (1995). The relationship of abuse characteristics to symptoms in sexually abused girls. Journal of Interpersonal Violence 10, 259-274. doi:10.1177/088626095010003002

Messman-Moore, T. L., \& Long, P. J. (2000). Child sexual abuse and revictimization in the form of adult sexual abuse, adult physical abuse, and adult psychological maltreatment. Journal of Interpersonal Violence, 15, 489-502. doi:10.1177/088626000015005003 
Messman-Moore, T. L., \& Long, P. J. (2003). The role childhood sexual abuse sequelae in the sexual revictimization of women: An empirical review and theoretical reformulation. Clinical Psychology Review, 23, 537-571. doi:10.1016/S0272-7358(02)00203-9

Mian, M., Marton, P., \& LeBaron, D. (1996). The effects of sexual abuse on 3- to 5-year-old girls. Child Abuse and Neglect, 20, 731-745. doi:10.1016/0145-2134(96)00061-0

Naugle, A. E. (1999). Identifying behavioral risk factors for repeated victimization using videotaped stimulus materials. Unpublished doctoral dissertation, University of Nevada, Reno.

Noll, J. G., Horowitz, L. A., Bonanno, G. A., Trickett, P. K., \& Putman, F. W. (2003). Revictimization and self-harm in females who experienced childhood sexual abuse. Journal of Interpersonal Violence, 18, 1452-1471. doi:10.1177/0886260503258035

Noll, J. G., Trickett, P. K., \& Putnam, F. W. (2003). A Prospective Investigation of the Impact of Childhood Sexual Abuse on the Development of Sexuality. Journal of Consulting and Clinical Psychology, 71, 575-586. doi:10.1037/0022-006X.71.3.575

Prevent Child Abuse America. (2013). Fact sheet: Sexual abuse of children. Retrieved from: https://www.childwelfare.gov/pubpdfs/preventingcan.pdf

Reese-Weber, M., \& Smith, D. M. (2011). Outcomes of child sexual abuse as predictors of later sexual victimization. Journal of Interpersonal Violence, 26, 1884-1905. doi:10.1177/0886260510372935

Risin, L. E., \& Koss, M. P. (1988). The sexual abuse of boys: Childhood victimizations reported by a national sample. In A. W. Burgess (Ed.), Rape and sexual assault II. New York: Garland. 
Roche, D. N., Runtz, M. G., \& Hunter, M. A. (1999). Adult attachment a mediator between child sexual abuse and later psychological adjustment. Journal of Interpersonal Violence, 14, 184-207. doi:10.1177/088626099014002006

Schachner, D. A., \& Shaver, P. R. (2004). Attachment dimensions and sexual motives. Personal Relationships, 11, 135-265. doi:10.1111/j.1475-6811.2004.00077.x

Slotter, E. B., \& Finkel, E. J. (2009). The strange case of sustained dedication to an unfulfilling relationship: Predicting commitment and breakup from attachment anxiety and need fulfillment within relationships. Personality and Social Psychology Bulletin, 35, 85100. doi:10.1177/0146167208325244

Slotter, E. B., \& Gardner, W. L. (2012). How needing you changes me: The influence of attachment anxiety on self-concept malleability in romantic relationships. Self and Identity, 11, 386-408. doi:10.1080/15298868.2011.591538

Soler-Baillo, J. M., Marx, B. P., \& Sloan, D. M. (2005). The psychophysiological correlates of risk recognition among victims and non-victims of sexual assault. Behavior Research and Therapy, 43, 169-181. doi:10.1016/j.brat.2004.01.004

Sroufe, L. A. (2005). Attachment and development: A prospective, longitudinal study from birth to adulthood. Attachment \& Human Development, 7, 349-367. doi:10.1080/14616730500365928

Stolenborgh, M., van IJzendoorn, M. H., Euser, E. M., \& Bakermans-Kranenburg, M. J. (2011). A global perspective on child sexual abuse: Meta-analysis of prevalence around the world. Child Maltreat, 16, 79-101. doi:10.1177/1077559511403920 
Townsend, C., \& Rheingold, A. (2013). Estimating a child sexual abuse prevalence rate for practitioners: A review of child sexual abuse prevalence studies. Charleston, S. C., Darkness to Light. Retrieved from www.d2l.org.

Tremblay, C., Hebert, M., \& Piche, C. (1999). Coping strategies and social support as mediators of consequences in child sexual abuse victims. Child Abuse and Neglect, 23, 929-945. doi:10.1016/S0145-2134(99)00056-3

Tyler, K. A. (2002). Social and emotional outcomes of childhood sexual abuse: A review of recent research. Aggression and Violent Behavior, 7, 567-589. doi:10.1016/S1359-1789(01)00047-7

Vanzile-Tamsen, C., Testa, M., \& Livingston, J. A. (2005). The impact of sexual assault history and relationship context on appraisal of and responses to acquaintance sexual assault risk. Journal of Interpersonal Violence, 20, 813-832. doi:10.1177/0886260505276071

Waters, E., Weinfield, N. S., \& Hamilton, C. E. (2000). The stability of attachment security from infancy to adolescence and early adulthood: General discussion. Child Development, 71, 703-706. doi:10.1111/1467-8624.00175

Wilson, A. E., Calhoun, K. S., \& Bernat, J. A. (1999). Risk recognition and trauma-related symptoms among sexually revictimized women. Journal of Counseling and Clinical Psychology, 67, 705-710. doi:10.1037/0022-006X.67.5.705

Yalom, I. D., \& Leszcz, M. (Collaborator). (2008). The theory and practice of group psychotherapy $\left(5^{\text {th }}\right.$ ed). New York: Basic Books. 


\section{APPENDIX A: VIGNETTE}

\section{Scene 1}

M: Hi cutie!

W: Hello :)

M: I saw you go to ISU. So do I. What do you study?

$\mathrm{W}$ : Working on getting my degree in business administration. What about you?

M: Thinking about declaring a bio major

W: Oh, that's cool. Why do you want to do that?

M: I like science. But let's not talk about school :p What are some things you like to do?

$\mathrm{W}$ : I guess in my free time I like to go out with my friends.

M: Sweet. You look really familiar. Have we had a class together?

W: I was thinking the same thing! Maybe it was speech last year?

M: That's it! So, do you wanna go out sometime?

Are you comfortable in this interaction?

Would you continue this interaction?

\section{Scene 2}

W: Maybe. I'll have to see when I'm free

M: You're so beautiful.

W: Thanks. So, what did you think of the personal history presentation we had to give for class?

M: Public speaking isn't really my thing but I would have loved to hear yours. Guess you'll just have to fill me in when we hang out. ;)

W: Haha I'm not sure my speech was worth reliving

M: If I got to look at you I'm sure any speech would be worth listening to.

W: Haha, yeah okay.

M: So what are you doing tonight?

Are you comfortable in this interaction?

Would you continue this interaction?

\section{Scene 3}

W: I'm getting ready to go out with my friends.

M: I bet you look so fine. Maybe we can meet up later ;)

W: Ha, we're having a girls' night. I'm not sure they'd be into me inviting a guy along tonight but maybe another time

M: You should send me a pic so I can see how good you look.

$\mathrm{W}$ : I usually like to get to know guys better before I give out pics

M: Guess we'll just have to get to know each other then :)

W: Haha I suppose that is one solution. :p

M: Exactly! :) So we should hang out tonight. Where will you and your friends be going?

\section{Are you comfortable in this interaction?}


Would you continue this interaction?

\section{Scene 4}

W: I'm not sure yet. We don't have concrete plans.

M: You gotta let me know so we can have fun tonight :) Can I get your ChatSnap?

$\mathrm{W}$ : My username is collegegrlxoxo add me.

M: Sweet! I just added you.

*Conversation ends and $\mathrm{W}$ meets friends at bar and gets the following message on ChatSnap* M: So, where did you and your friends decide to go?

Are you comfortable in this interaction?

Would you continue this interaction?

\section{Scene 5}

W: We're uptown.

M: I see on my ChatSnap map that you're at the bar. I'll be there soon.

W: Oh, uhhh... Okay.

*guy shows up at the same bar*

* guy approaches girl in person*

M: Hey there. You look fine tonight.

W: *blushes* Oh. Thanks.

M: Let's dance

W: I'm kinda hanging out with my friends right now. I don't want to ditch them.

M: Come on. I want to get closer to you.

Are you comfortable in this interaction?

Would you continue this interaction?

\section{Scene 6}

W: Okay, fine.

*guy and girl dance together*

M: Come closer

$\mathrm{W}$ : Actually, I'm going to get another drink.

M: I'll come with you.

*they get another drink and then go back to dancing*

M: You're so hot. And you're such a good dancer.

$\mathrm{W}$ : Thanks. I wonder where my friends are.

M: Who cares. We're having such a good time together.

W: Wow, it's getting really hot in here. I think I'm going to step outside.

M: I agree. I'll come with you. 
Are you comfortable in this interaction?

Would you continue this interaction?

\section{Scene 7}

*they go outside*

W: Actually, I think maybe my friends went home already. I'm not really feeling well so I think

I'm going to head out.

M: Are you okay? I'll walk you home.

W: Are you sure? You don't really need to do that.

M: Of course, wouldn't want you walking alone at night.

Are you comfortable in this interaction?

Would you continue this interaction?

\section{Scene 8}

W: Well... Okay, thanks

*guy grabs girls hand and walks her home*

$\mathrm{W}$ : Well, this is my place. Thanks for walking me home.

M: No problem. Actually, do you mind if I come inside for a second?

Are you comfortable in this interaction?

Would you continue this interaction?

\section{Scene 9}

W: Oh, um I think my roommates are home.

M: I don't see any lights on. I think we'll be fine *winks*

$\mathrm{W}$ : Alright, I guess that would be okay for a little while.

*they walk into her apartment*

M: I like your apartment.

W: Thanks!

M: The part I like most is that we're here alone.

W: Yeah.. I think my roommates will be home soon.

M: Let's sit down on the couch.

Are you comfortable in this interaction?

Would you continue this interaction?

Scene 10 
W: Umm... sure I'll stream a movie

* the two sit on the couch together*

M: I'm so glad we ran into each other tonight.

*guy kisses girl*

* guy moves closer to girl and kisses her more, she kisses back*

M: You're a great kisser.

W: Thanks. I'm going to go ahead and start the movie

*the movie starts*

M: You are so beautiful.

*guy kisses girl*

M: I am so turned on.

Are you comfortable in this interaction?

Would you continue this interaction?

\section{Scene 11}

* guy unbuttons girl's shirt*

*she pulls back*

W: Whoa, let's slow down.

M: *moans* Come on ...

*he continues to kiss her*

W: I hardly know you. We should just watch the movie.

M: I am so into you. I want to make you feel so good.

Are you comfortable in this interaction?

Would you continue this interaction?

\section{Scene 12}

*Guy kisses girl and begins to rub her breasts*

M: You feel so great

W: I'm not ready for this yet

M: But I'm so turned on

Are you comfortable in this interaction?

Would you continue this interaction?

Scene 13 
*guy unbuttons girl's pants*

W: Okay ... seriously... please stop.

M: But this feels so good. We shouldn't stop now

Are you comfortable in this interaction?

Would you continue this interaction? 


\section{APPENDIX B: RESEARCH PARTICIPANT INFORMED CONSENT}

\section{Research Participant Informed Consent}

\section{PLEASE READ THIS DOCUMENT CAREFULLY. SIGN YOU NAME BELOW ONLY IF YOU AGREE TO PARTICIPATE. YOUR SIGNATURE IS REQUIRED FOR PARTICIPATION. YOU MUST BE 18 YEARS OF AGE TO PARTICIPATE.}

\section{Description of the Study:}

This study will ask you to select dating profiles of interest to you, complete a brief online dating profile, complete questionnaires online, and read a vignette about two individuals who meet online dating.

Nature of Participation: You will spend approximately 45 - 60 minutes completing the tasks.

Purpose of the Study: You will be provided with an explanation of the study following the last task.

Possible Risks: When completing the questionnaires, you may come across a question or group of questions that you find unpleasant or upsetting. For instance, a few questions may cause you to think about painful past experiences and/or negative emotional states. You will be asked to provide confidential information about yourself, including information pertaining to past sexual experiences and drug use. In the event that you do become upset, a research assistant will remind you that you can withdraw from the study. If needed, a researcher will take you to the Student Counseling Services building. Researchers will provide you with a list of local resources who can help you. Although code numbers will be used, there is also a slight risk of loss of confidentiality. You will provide a brief online dating profile that may have identifying information, however, that specific information will be deleted at the conclusion of the study.

Possible Benefits: This study will allow participants to contribute to the understanding of online dating and relationship development among young adults as an outcome of past experiences and individual characteristics. If you desire to be informed about the outcome of this study, you can contact the researcher through the information listed below.

Compensation for your time: You will receive extra credit in a psychology course through the SONA system. You will receive extra credit simply by virtue of coming to your appointment; you are free to withdraw your participation at any time without penalty.

Confidentiality: Your study materials have been assigned a code number that will protect your identity. All data will be kept in secured files, in accord with the standards of the University, Federal regulations, and the American Psychological Association. Finally, it is no individual person's responses that interest us; we are studying people in general.

Opportunities to Question: Any technical questions about this research may be directed to Dr. Marla Reese-Weber at 438-3743. Any questions regarding your rights as a research participant or 
research-related injuries may be directed to ISU's Office of Research Ethics and Compliance (309) 438-2529.

Opportunities to Withdraw: If you decide now or at any point to withdraw this consent or stop participation, you are free to do so at no penalty to yourself. You are free to skip specific questions and continue participating at no penalty.

Opportunities to be Informed of Results: In all likelihood, the results will be fully available around the summer of 2019. If you wish to be told the results of this research, please contact Dr. Marla Reese-Weber at 438-3743. She will either meet with you to discuss the results or direct you to a copy of the results. In addition, there is a chance that the results from this study will be published in a scientific psychology journal, which would be available in many libraries. In such an article, participants would be identified in general terms such as "college students."

I consent to participate in this study.

Signature

Date

Print name here 


\section{APPENDIX C: PROCEDURE}

*Participant arrives at study session.*

Researcher (R): "Hi, are you ___ here for the Online Dating study?"

Participant (P): "Yes."

R: "Alright, so I'd like to start by giving you a rundown of how the study will go, and then have you look over the consent forms. The study will take about 30-45 minutes to complete. The purpose of the study is to test an algorithm for matching people on online dating sites. There are three main parts to this study.

1. you will read and select dating profiles as well as write a bio for yourself

2. you will answer some questionnaires

3. you will read a scenario about a online dating interaction and answer some questions." "Here's the informed consent form."

*Researcher hands informed consent form to participant.*

"Please read that over, let me know if you have any questions, and then, if you agree to participate, go ahead and sign it."

*Participants reads informed consent form and signs.*

R: "Alright, before we move forward, I just wanted to highlight that your participation is voluntary and you are free to stop participating in the study at any time without any penalty towards you."

$\mathrm{R}: *$ Starts Qualtrics survey.*

"Before we start, I want to reassure you that all of the instructions I give you will also be on the computer as you go through the tasks."

“Okay, so I'll have you start by viewing the profiles and selecting which individuals you would hypothetically be interested in talking with. There will be 10 profiles that contain a picture and a brief bio. You need to select 5 you'd be interested in meeting if you were really considering using an online dating site/app."

After that go ahead and click the next button. It will take you to the section where you fill out the bio the way you would for an online dating profile. You will have 500 characters to convey whatever you want about yourself. I want to reiterate from the informed consent form that this information will not be connected to your name so the researchers will not know whose bio belongs to you."

"When you're finished with your bio, click the next button and then you will complete the questionnaires."

"Do you have any questions about these first two parts?" 
*If yes, research assistant answers questions.*

R: "Okay, I will be waiting in the hallway. Let me know when you have finished the questionnaires."

*Participant completes questionnaires*

R: Okay, now that all your information has been submitted, let's who's a match with you.

*Researcher randomly selects rejection or nonrejection condition.

- If rejection condition, "looks like you 2 matches of 10 , only one of those is one that you selected as your 5."

- If non-rejection condition, "looks like you have 8 matches of 10 , four of those are ones that you selected as your 5."

$\mathrm{R}$ : "Okay, so for this next part you are going to read through a scenario of two people meeting online. The story is broken up into sections so that every so often it stops to ask you some questions. It is always going to ask you if you would be comfortable in this situation and if you were in this situation would you continue with the interaction. Again, try to imagine that you are the woman in the situation and how you would feel and what you would do, if you were really considering using an online dating site. Do you have any questions?"

*If yes, research assistant answers questions.*

R: "I'll be in the hall so come and get me when you are finished."

*Researcher leaves participant to go through vignette.*

*Participant completes vignette and notifies research assistant.*

R: "We are now done with the study." Then, ask the following questions:

What did you think of the study?

What did you think of questionnaires you completed today?

Were the questions familiar?

Do you have any ideas about how those questionnaires and activities might be related to what you did today?

Was any part of the study upsetting to you?"

*After discussing participant's responses with him/her, tell the participant*,

"We are interested in finding out how individual differences might be related to different reactions during dating or risky situations. Individual differences include personal history, personality characteristics, and reactions to rejection. To do this, we asked you to complete several questionnaires but we also tricked you. There is no algorithm we are testing. We had you select profiles and create a bio for yourself so that we could 
randomly assign you to the rejection or non-rejection condition. Those assigned to the rejection group were told they only had 2 matches and those assigned to the non-rejection group were told they had 8 matches. We will be examining how rejection might influence perception of a potentially risky situation like the one in the vignette that you read.

Does that make sense? Do you have any questions for me?"

*If yes, research assistant answers questions.*

R: "Here is a debriefing statement that also explains the study and provides some contact information if you have questions about the study or experienced distress following this procedure."

* Hands them debriefing statement

R: "We need to ask one more thing of you: Could you please refrain from telling your friends and classmates about this study? We have many more participants to test in this study and we want all of them to experience it with fresh eyes. Could you do that for us?"

R: "Thank you for participating in this study. Your extra credit should be posted to SONA within the next few days." 